${ }^{* * * *}$ Note: The Supporting Information published with the original paper contained errors in Section A3. The SI that follows is a corrected version posted September 22, 2005. ${ }^{\star \star \star \star}$

\title{
Agonists and Partial Agonists of Rhodopsin: Retinals with Ring Modifications
}

Reiner Vogel, Friedrich Siebert, Steffen Lüdeke, Amiram Hirshfeld, and Mordechai Sheves

\section{Figure A1: Meta I/Meta II of rhodopsin and isorhodopsin}

Comparison of the Meta I/Meta II titration curves obtained at $10{ }^{\circ} \mathrm{C}$ of rhodopsin (black circles) and isorhodopsin (gray circles) obtained by UV-vis spectroscopy. Within the limits of experimental error, the $\mathrm{pK}_{\mathrm{A}}$ values are identical (7.1) for both pigments.

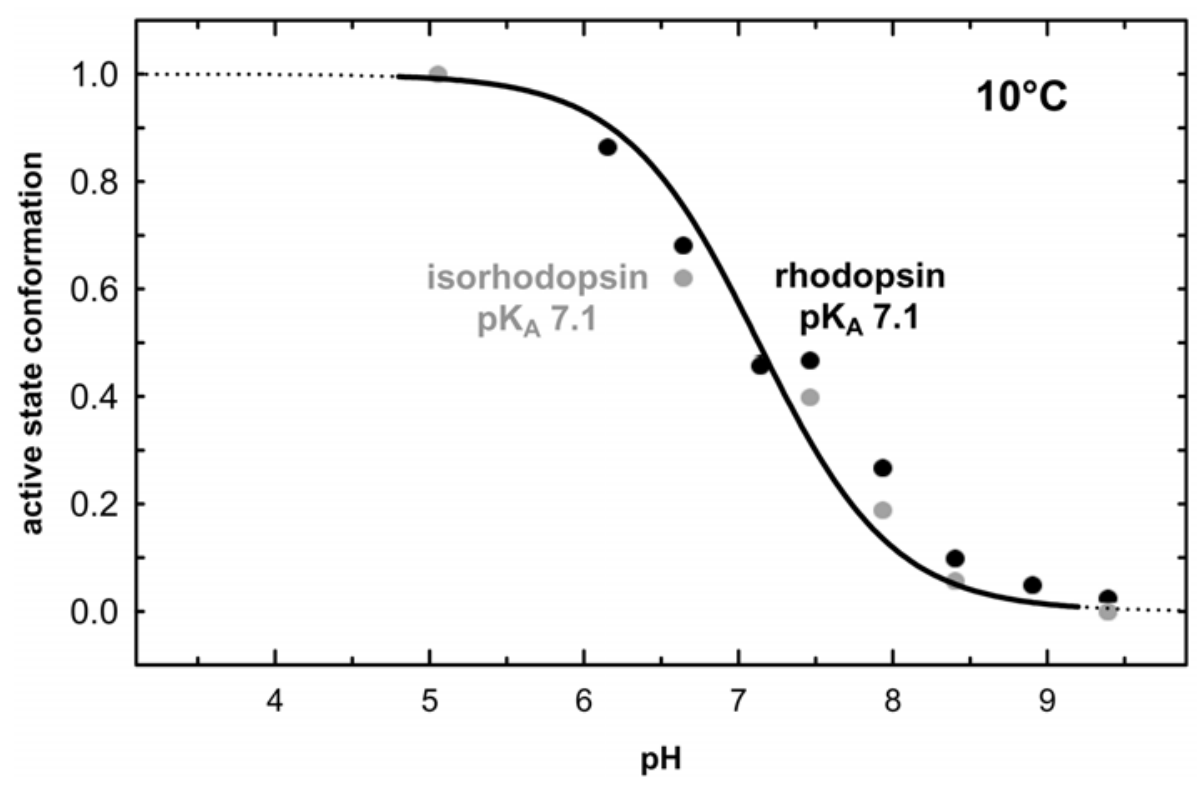


Figure A2: Meta I and Meta II with the acyclic-2 ligand

A. Meta I (low temperature) and Meta II FTIR difference spectra of acyclic-2 (black) were obtained at $10{ }^{\circ} \mathrm{C}, \mathrm{pH} 7.0$, and $30^{\circ} \mathrm{C}, \mathrm{pH} 4.0$, respectively, and are compared to spectra of acyclic-1 (gray) obtained under same conditions. The spectra of acyclic-2 and acyclic-1 are very similar and only small variations regarding band intensities can be observed, while peak positions are conserved. $B$. The $\mathrm{pK}_{\mathrm{A}}$ of the Meta I/Meta II equilibrium of acyclic-2 is 5.0 at $20^{\circ} \mathrm{C}$ and thus similar to that of acyclic-1 (4.8).
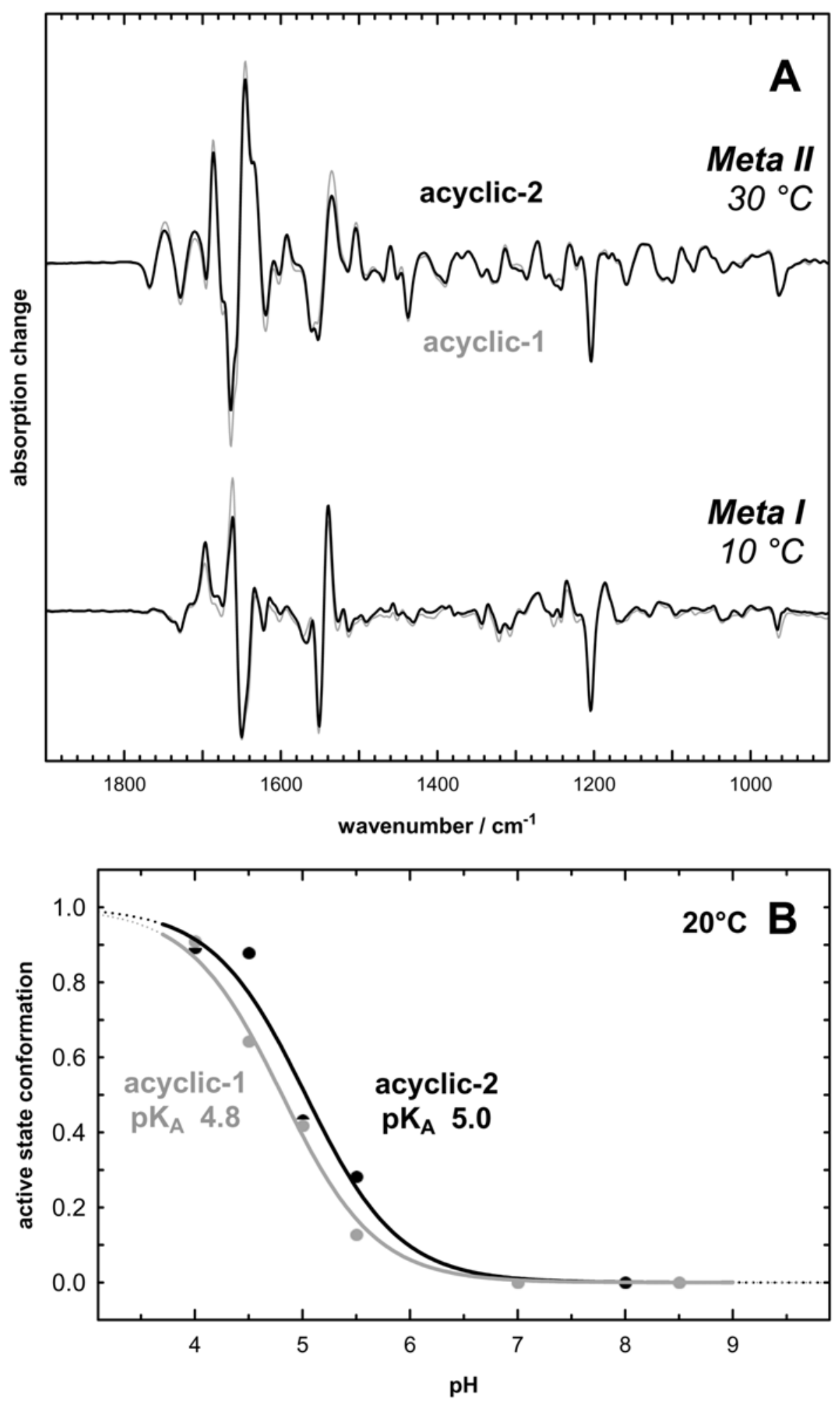


\section{Section A3: Calculation of $\Delta \mathrm{H}$ and $\Delta \mathrm{S}$}

In the following section we will derive equations to calculate the enthalpy change $\Delta \mathrm{H}$ and the entropy change $\Delta \mathrm{S}$ of the Meta I/Meta II equilibrium ( $\mathrm{MI}$ and $\mathrm{MII}$ in the following) from the measured $\mathrm{pK}_{\mathrm{A}}$ values of the transition at two different temperatures $T_{1}$ and $T_{2}$. Starting from the reaction

$\mathrm{MI}+\mathrm{H}^{+} \leftrightarrow \mathrm{MII}$

we derive

$\frac{[\mathrm{MII}]}{[\mathrm{MI}]\left[\mathrm{H}^{+}\right]}=\mathrm{K}_{\text {eq }}=\mathrm{e}^{-\Delta \mathrm{G} / \mathrm{RT}}$, with $\Delta \mathrm{G}=\Delta \mathrm{H}-\mathrm{T} \Delta \mathrm{S}$, where $\mathrm{K}_{\text {eq }}$ is the equilibrium constant between $\mathrm{MI}$ and $\mathrm{MII}, \mathrm{T}$ is the absolute temperature, $\mathrm{R}$ is the gas constant, and $\Delta \mathrm{G}$ is the Gibbs free energy change of the transition.

Taking the logarithm of this equation yields

(1) $\quad \ln \mathrm{K}_{\text {eq }}=\frac{-\Delta \mathrm{G}}{\mathrm{RT}}=\frac{-\Delta \mathrm{H}}{\mathrm{RT}}+\frac{\Delta \mathrm{S}}{\mathrm{R}}$

Solving this equation for $\Delta \mathrm{S}$ yields

(2) $\Delta \mathrm{S}=\mathrm{R} \ln \mathrm{K}_{\mathrm{eq}}+\frac{\Delta \mathrm{H}}{\mathrm{T}}$.

Evaluating (1) for two different temperatures $T_{1}$ and $T_{2}$ yields

$\ln K_{\text {eq } 1}=\frac{-\Delta \mathrm{H}}{\mathrm{RT}_{1}}+\frac{\Delta \mathrm{S}}{\mathrm{R}}$ and $\ln \mathrm{K}_{\mathrm{eq} 2}=\frac{-\Delta \mathrm{H}}{\mathrm{RT}_{2}}+\frac{\Delta \mathrm{S}}{\mathrm{R}}$.

Assuming $\Delta \mathrm{H}$ to be independent of temperature over the considered range, we can form the difference between these two expressions

$$
\begin{aligned}
& \operatorname{InK}_{\text {eq } 2}-\ln K_{\text {eq } 1}=\frac{-\Delta H}{R}\left(\frac{1}{T_{2}}-\frac{1}{T_{1}}\right) \text { and thus } \\
& \text { (3) } \Delta \mathrm{H}=-\mathrm{R} \frac{\ln \mathrm{K}_{\text {eq } 2}-\ln \mathrm{K}_{\text {eq } 1}}{\frac{1}{\mathrm{~T}_{2}}-\frac{1}{\mathrm{~T}_{1}}}=\mathrm{R}\left(\ln \mathrm{K}_{\text {eq } 2}-\ln \mathrm{K}_{\text {eq } 1}\right) \frac{\mathrm{T}_{1} \mathrm{~T}_{2}}{\mathrm{~T}_{1}-\mathrm{T}_{2}} .
\end{aligned}
$$

To derive the equilibrium constants $\mathrm{K}_{\text {eq }}$ from our data, we use the Henderson-Hasselbalch equation

$$
\mathrm{pK}=\mathrm{pH}+\log _{10} \frac{[\mathrm{MII}]}{[\mathrm{MI}]}=\log _{10} \frac{[\mathrm{MII}]}{[\mathrm{MI}]\left[\mathrm{H}^{+}\right]}=\log _{10} \mathrm{~K}_{\text {eq }} \text {, which yields } \mathrm{K}_{\text {eq }}=10^{\mathrm{pK}} \text { and }
$$

(4) $\quad \ln K_{\text {eq }}=(\ln 10) p K$, where $\mathrm{pK}$ is the $\mathrm{pK}_{\mathrm{A}}$ of the $\mathrm{MI} / \mathrm{MII}$ equilibrium at a given temperature.

Inserting (4) into (3) yields the following expression for $\Delta \mathrm{H}$ (with $\ln 10 \approx 2.303$ ) 
(5) $\quad \Delta \mathrm{H}=\mathrm{R} \cdot 2.303 \cdot\left(\mathrm{pK}_{1}-\mathrm{pK}_{2}\right) \cdot \frac{\mathrm{T}_{1} \mathrm{~T}_{2}}{\mathrm{~T}_{1}-\mathrm{T}_{2}}$

Evaluating (2) at $\mathrm{T}_{2}$ and insertion of (4) and (5) yields the following expression for the change of entropy of the transition at a given $\mathrm{pH}$

$$
\Delta S=R \ln K_{\text {eq }}+\frac{\Delta H}{T}=R \cdot 2.303 \cdot\left(\mathrm{pK}_{2}+\left(\mathrm{pK}_{1}-\mathrm{pK}_{2}\right) \cdot \frac{\mathrm{T}_{1} \mathrm{~T}_{2}}{\left(\mathrm{~T}_{1}-\mathrm{T}_{2}\right) \cdot \mathrm{T}_{2}}\right)
$$

This expression can be simplified by algebraic transformations to

(6) $\Delta \mathrm{S}=\mathrm{R} \cdot 2.303 \cdot\left(\frac{\mathrm{pK}_{1} \mathrm{~T}_{1}-\mathrm{pK}_{2} \mathrm{~T}_{2}}{\mathrm{~T}_{1}-\mathrm{T}_{2}}\right)$

Turning back to (5), the experimental error of $\Delta \mathrm{H}$ stems largely from the error of $\mathrm{pK}_{2}-\mathrm{pK}_{1}$. As mentioned in the Material and Methods, the error for the single $\mathrm{pK}_{\mathrm{A}}$ values is estimated to be less than 0.2 units, being mostly due to difficulties in determining a pure Meta II state. As both $\mathrm{pK}_{1}$ and $\mathrm{pK}_{2}$ were derived with the same basis spectrum of Meta II for each pigment, the inherent error is a systematic error. We therefore estimate the error margin for the difference to be at maximum 0.2 units. This yields an absolute error for $\Delta \mathrm{H}$ of at maximum $15 \mathrm{~kJ} / \mathrm{mol}$. Turning to equation (2), $\Delta \mathrm{S}$ consists of two terms, of which the second contributes predominantly to the error, such that the experimental error stems largely from the error in determining $\Delta \mathrm{H}$. The experimental error for $\Delta \mathrm{S}$ is therefore within approximately $54 \mathrm{~J} / \mathrm{mol} \cdot \mathrm{K}$. 